Conf- $941013-26$

UCRL-JC-116965

PREPRINT

\title{
Comparison of the Calculated and Measured Stability of a NbTi Cable-In-Conduit Conductor
}

\author{
Robert L. Wong and Chris T. Yeaw
}

This paper was prepared for submittal to the IEEE Transactions on Applied Superconductivity and

the Applied Superconductivity Conference Boston, MA

October 16-21, 1994

October 13, 1994

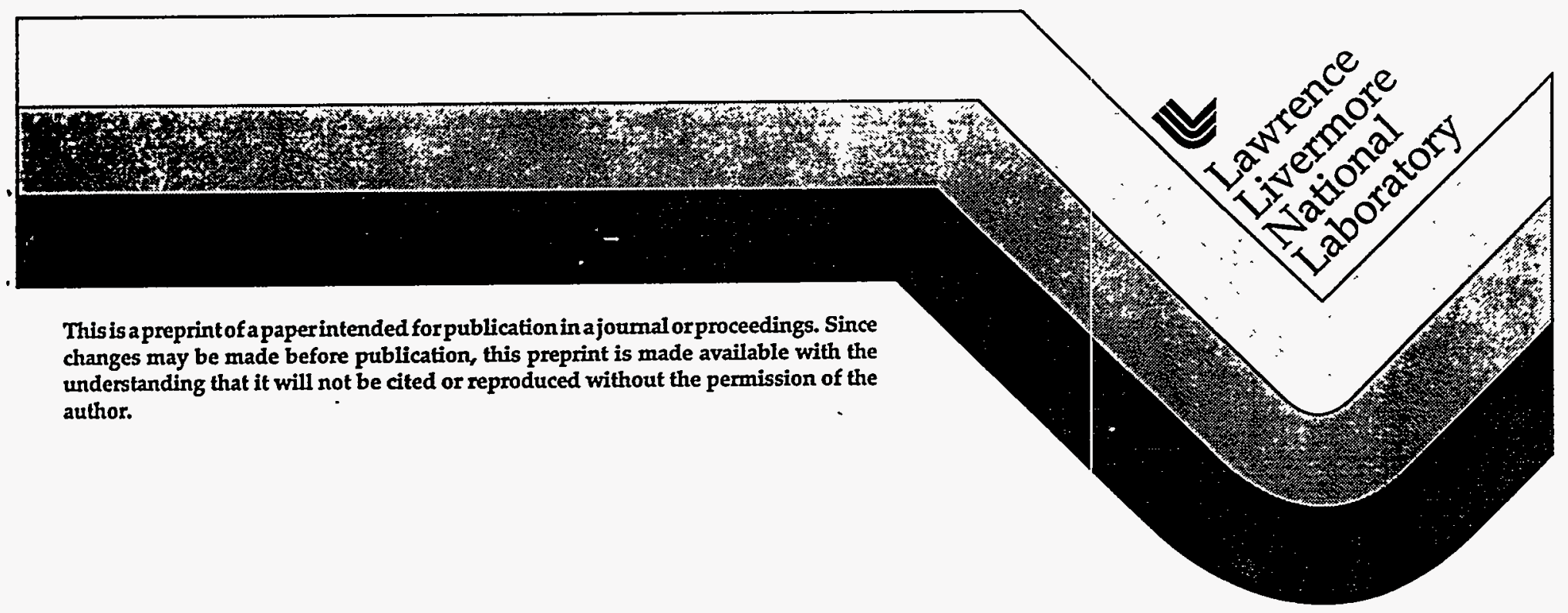


This document was prepared as an account of work sponsored by an agency of the Linited Stales Government. Neither the linited Slates Government nor the University of California nor any of their emplojees. makes any warranty; express or implied, or assumes any legal liability of responsibility for the accurac: completeness, or usefulness of any information, apparatus, product, or process disclosed, or represents that its use would not infringe privately owned rights. Reference herein to any specific commercial products, process, or service by trade rame. trademark, manufacturer, or otherwise, does not necessarily constitute or imply its endorsement, recommendation. of favoring by the United States Government or the University of California. The views and opinions of authors expressed herein do not necessarily state or refleet those of the United States Government or the University of Californiz, and shall not be used for advertising or product endorsement purposes. 


\section{DISCLAIMER}

Portions of this document may be illegible in electronic image products. Images are produced from the best available original document. 


\title{
Comparison of the Calculated and Measured Stability of a NbTi Cable-In-Conduit Conductor:
}

\author{
Robert L. Wong \\ Lawrence Livermore National Laboratory, Livermore, CA \\ Chris T. Yeaw \\ Nuclear Engineering and Engineering Physics, University of Wisconsin, Madison, WI
}

\begin{abstract}
Calculated curves of cable-in-conduit conductor energy stability margins vs. current are compared to experimental curves obtained at Oak Ridge National Laboratory for NbTi single triplex conductors. The conductors ranged in length from $1.8 \mathrm{~m}$ to $4.8 \mathrm{~m}$, and had no imposed helium flow. The initiating heat pulse was applied for $16.7 \mathrm{~ms}$ over the entire conductor length.

The calculated stability curves display the large decrease in energy margin from the low current and high energy margin "well-cooled" stability region, to the high current and low energy margin "ill-cooled" region that was determined experimentally. The calculated "limiting current" of 250 A (boundary between the ill-cooled and well-cooled regions) also agrees with experiment. The multi-valued stability margins measured for lengths of 3.1 and $3.8 \mathrm{~m}$ could not be obtained by the computer model. Excluding the multiple stabilities, the calculated margins are generally $30 \%$ lower than the experimental values.

The decrease in energy margin in the ill-cooled region was found to be due to the low critical to operating temperature difference $(2.2 \mathrm{~K}$ at $250 \mathrm{~A})$. This prevents an initiating pulse in the ill-cooled region from being able to generate significant Joule heating without quenching, limiting the energy margin.
\end{abstract}

\section{INTRODUCTION}

Lue, Miller, and Dresner (Oak Ridge National Laboratory, ORNL) [1,2] made stability measurements on NbTi single triplex CICC conductors, applying the initiating heat pulse to the full conductor length using an embedded soldered heater wire. Dresner obtained analytic estimates of the limiting current [3], and for the magnitude of the thermally induced sonic waves without friction [4].

Models have been formulated that do predict multiple stabilities. In order for a model to predict multiple stabilities it must have the ability to induce turbulent flows, since laminar heat transfer coefficients are not a function of velocity (Graetz problem). Bottura and Minervini [5] developed an approximate model that uses the average induced velocity at the quench initiation region (no flow stagnation).

Manuscript received October 19, 1994.

This work was performed under the auspices of the U.S. Department of Energy by the Lawrence Livermore National Laboratory under Contract W7405-Eng-48.
Their model compares favorably with the ORNL tests. Kamitani, et.al. [6] developed a computer model that solves all of the basic conservation equations. They generated curves containing multiple stabilities. Possibly their large mesh size ( $1 \mathrm{~m}$ long elements with a $1 \mathrm{~m}$ long initial quench zone, IQ) made the multiple stability solutions possible. The CICC code [7] used in the present analysis was able to calculate multiple stabilities for the US-DPC conductor quench initiating near the inlet end [8]. The limiting current predicted by this calculation agreed with experiment. Initiation near the end of the conductor generated the necessary turbulent helium flow after the pulse for multiple stabilities. The low copper/superconductor ratio (1.17) and the low copper RRR (27) provided conditions for the existence of an ill-cooled region, even with $\mathrm{Nb}_{3} \mathrm{Sn}$.

\section{ANALYSIS}

The simulations were made using computer code CICC [7], which describes the conductor using the onedimensional energy, Inomentum, and mass conservation equations in the heliurn, and the axisymmetric conduction equations in the solid. Calculated stability curves of energy margin vs. current were compared with experimental curves from single NbTi triplex conductors obtained by Lui and Miller and presented in Fig. 6 of [2]. The conductor perimeters are listed in [1]. The tests used had a field of 7.0 $\mathrm{T}$, an initial helium temperature of $4.2 \mathrm{~K}$, an initial pressure of $5.0 \mathrm{~atm}$, and no imposed helium flow. Conductor lengths of $1.8 \mathrm{~m}, 3.1 \mathrm{~m}, 3.8 \mathrm{~m}$, and $4.8 \mathrm{~m}$ were considered. The heat pulse was applied to the strand over the entire conductor length for $16.7 \mathrm{~ms}$.

Figs. 1-4 show the experimental and the calculated stability curves for the $1.8 \mathrm{~m}, 3.1 \mathrm{~m}, 3.8 \mathrm{~m}$ and $4.8 \mathrm{~m}$ long conductors. Generally, the calculated results are about $30 \%$ below the experimental values. However the code was not able to calculate the multiple stabilities experimentally found in the 3.1 and $3.8 \mathrm{~m}$ length conductors. The available cablespace enthalpy, cable-space internal energy, and conductor strand energy are also shown. The available strand energy, which contributes less than $1 \%$ to the cable-space energy, includes the energy of the heater wire and the solder attaching the heater to the strands. The energies are all integrated from $4.2 \mathrm{~K}$ to current sharing temperature [9]. The helium enthalpy is evaluated at a pressure of $5 \mathrm{~atm}$ and the internal energy is evaluated at a density of $140.6 \mathrm{~kg} / \mathrm{m}^{3}$ 
(4.2 K, $5 \mathrm{~atm})$. These curves provide a measure of how well the conductor uses the available helium energy.

A summary of the calculated stability curves for the four conductor lengths is shown in Fig. 5. Since the laminar heat transfer coefficient that exists in the stagnation region (where the quench initiates) is not a function of velocity, there is little difference in the calculated stability of the four different length conductors. Small differences do develop in the well-cooled region below the $250 \mathrm{~A}$ limiting current due to differences in frictional flow resistance. The low friction in the $1.8 \mathrm{~m}$ conductor allows the helium to expand in response to the pressure generated during the pulse, making the helium enthalpy available. At $200 \mathrm{~A}$ the energy margin of the $1.8 \mathrm{~m}$ conductor is near the available cable-space enthalpy, indicating efficient use of the available enthalpy. The $4.8 \mathrm{~m}$ conductor has enough friction to prevent expansion during the pulse, so only the cable-space internal energy is available. At $200 \mathrm{~A}$ the energy margin of the 4.8 $\mathrm{m}$ conductor is near the available cable-space internal energy, indicating efficient use of the available energy. As the current increases above $250 \mathrm{~A}$ (ill-cooled region) the heat pulses become weaker, and the generated pressures become too weak to drive the helium expansion so the variation in stability for the different lengths vanishes. The large decrease in energy margin in the ill-cooled region decreases the efficiency of the conductor to the point that only $20 \%$ of the available internal energy is utilized.

Ref. [9] characterizes the well-cooled and ill-cooled stability regions, and investigates the reasons why the $\mathrm{TPX} / \mathrm{TF} \mathrm{Nb}{ }_{3} \mathrm{Sn}$ conductor stability curve does not exhibit the large decrease in energy margin from the well-cooled to illcooled regions that is exhibited by the ORNL conductor. In summary the energy margin in the well-cooled region is high since (in a marginal quench), the initiating heat pulse is stronger than the Joule heating after the pulse. The margin in the ill-cooled region is low since the initiating heat pulse is weaker than the Joule heating after the pulse. The limiting current occurs when the initiating heat pulse is the same strength as the Joule heating. It was concluded that the entire TPX/TF stability curve is well-cooled because the large $5.8 \mathrm{~K}$ critical to operating temperature difference allows the initiating heat pulse to generate a significant amount of Joule heating, even at high currents, while remaining stable. Being able to operate stabily with Joule heating during the heat pulse extends the well-cooled region into the high current range that would otherwise have been ill-cooled.

In contrast the ORNL NbTi conductor has a critical to operating temperature difference of only $2.2 \mathrm{~K}$ at $250 \mathrm{~A}$. This low critical to operating temperature difference does not allow Joule heating during the pulse if the conductor is operating much above the $250 \mathrm{~A}$ limiting current. Hence the Joule heating contribution to the pulse heating can be ignored in determining the limiting current. At $250 \mathrm{~A}$ in a marginal quench, the initiating heat pulse has the same strength as the Joule heating after the pulse (Fig. 6). In agreement, the $250 \mathrm{~A}$ limiting current is at the low current end of the ill-cooled region of the stability curve (Fig. 5). Fig. 6 does show a significant amount of Joule heating during the pulse; but by $275 \mathrm{~A}$, there is no Joule heating during a marginally stable pulse. Therefore the region above $250 \mathrm{~A}$ is ill-cooled, with the energy margin dropping an order of magnitude from the well-cooled value.

Even with the low critical to operating temperature difference, high energy margins and multiple stabilities could be obtained in the ill-cooled region with a high turbulent heat transfer coefficient. However the present ORNL conductor model cannot generate the turbulent convection that is necessary due to the simplifying assumptions that the cable-space geometry, superconductor parameters, and current are uniform in the conductor; and that the thermodynamic parameters of the strand and the helium vary only axially. The symmetry of this model causes the flow stagnation region from any thermally induced flows to remain stationary at the middle of the conductor length. The laminar heat transfer coefficient there (Fig. 7) is essentially only a function of time.

Since the model is symmetric and there is no imposed velocity, only the presence of significant induced sonic velocities could generate the helium velocities necessary for turbulent convection. Dresner [4] analytically showed that sonicly induced flow could attain speeds of a few meters per second. However to obtain an analytic solution, he had to neglect friction. Figs. 8 and 9 show the sonicly induced pressures and velocities in the middle of the conductor length. The short $1.8 \mathrm{~m}$ length has the least frictional damping. However even with this short conductor, the velocities in the middle of the conductor length are less than $0.002 \mathrm{~m} / \mathrm{s}$, much less than the $0.1 \mathrm{~m} / \mathrm{s}$ necessary to transition to turbulent flow.

The actual conductor has a complex very non-uniform cable-space geometry. Non-uniformities are also present in the superconductor critical current characteristics, in the heater characteristics, and in the current (due to local crosscurrents between strands). Also, parameter variations are likely very three-dimensional. These nonuniformities represent opportunities for high local turbulent cooling.

Multiple stabilities were experimentally measured [2] with conductor lengths of $2.3 \mathrm{~m}, 3.1 \mathrm{~m}$ and $3.8 \mathrm{~m}$, but not with lengths of $1.8 \mathrm{~m}$ and $4.8 \mathrm{~m}$. Initial tests were made with the longest $4.8 \mathrm{~m}$ length. The presence of laminar or turbulent cooling may offer an explanation for why multiple stabilities occurred for some lengths and not others. The shorter conductors were produced from the same sample by cutting sections off of the longer conductor [2]. In tests with the initial $4.8 \mathrm{~m}$ length, quench initiation occurred far enough away from the ends for friction to suppress any turbulent flow, so only the lower stability limit was obtained. As the conductor was cut, regions of quench initiation could have been exposed to the end of the conductor. The low frictional 
resistance to the open end could have made it possible for a higher energy pulse to generate the turbulent convective cooling necessary to obtain the upper stability limit, in manner similar to the US-DPC conductor model [8].

\section{CONCLUSION}

The energy margin drop in the ill-cooled region is the result of the low critical to operating temperature difference of the NbTi conductor. This limits the ability of the conductor to absorb, in the ill-cooled region, a stable initiating heat pulse that includes Joule heating. Hence the conductor can only absorb the energy that increases its temperature to current sharing. The higher critical temperature of the TPX/TF $\mathrm{Nb}_{3} \mathrm{Sn}$ conductor allows it to operate in the well-cooled region for the entire range of operating currents.

\section{REFERENCES}

[1] J. W. Lue, J. R. Miller, \& L. Dresner, "Stability of cablein-conduit superconductors," J. Appl. Phys., vol.51, no. 1, pp. 772-783, January 1980.

[2] J. W. Lue \& J. R. Miller, "Parametric study of the stability margins of cable-in-conduit superconductors: experiment," IEEE Trans. on Magnetics, vol. 17, no. 1, pp. 757-760, January 1981.

[3] L. Dresner, "Parametric study of the stability margin of cable-in-conduit superconductors: theory," IEEE Trans. on Magnetics, vol. 17, no. 1, pp. 753-756, January 1981.

[4] L. Dresner, "Heat-induced flows in cable-in-conduit conductors," Cryogenics, pp. 653-658, November 1979.

[5] L. Bottura and J. V. Minervini, "Modeling of dual stability in a cable-in-conduit conductor," IEEE Trans. on Magnetics, vol. 27, no. 2, pp. 1900-1903, March 1991.

[6] A. Kamitani, et.al., "Stability analysis of a forced-flow cooled superconducting coil: numerical simulation of multiple stability," Cryogenics, vol. 31, no. 2, February 1991.

[7] R. L. Wong, Program CICC, Flow and Heat Transfer in Cable-In-Conduit Conductors, LLNL rept. UCRL101241, 13th Symp. on Fusion Engineering, October 2$6,1989$.

[8] R. L. Wong, et.al., Numerical Simulation of the Stability in a Cable-In-Conduit Conductor Developed for FusionMagnet Applications, LLNL rept. UCRL-JC-107258, 14th Symp. on Fusion Engineering, Sept. 30- Oct. 3, 1991.

[9] R. L. Wong, Stability Analysis of the TPX Toroidal Field Coil, 1994 Applied Superconductivity Conference, October 1994.

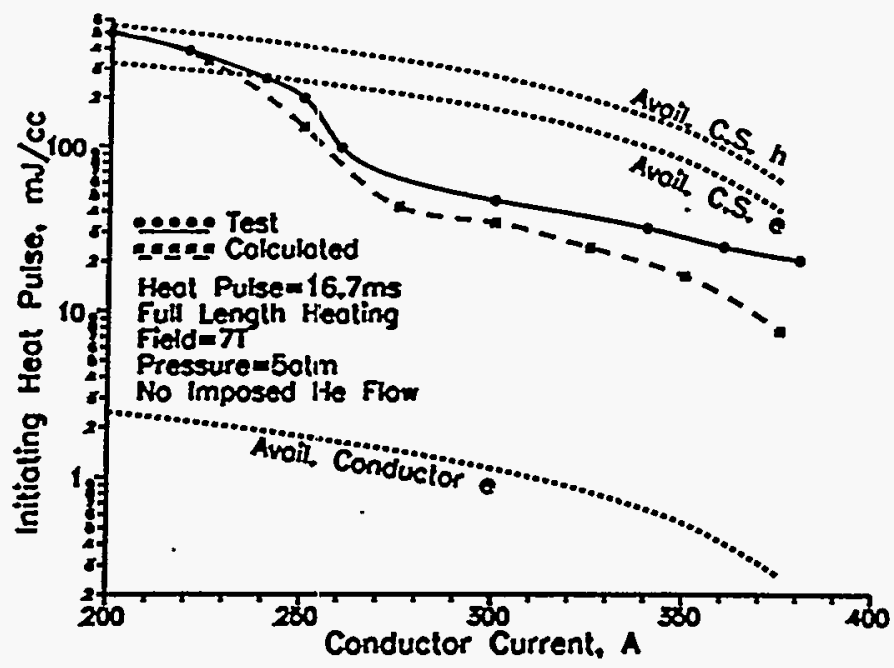

Fig. 1. ORNL NbTi triplex conductor stability, $1.8 \mathrm{~m}$ conductor length

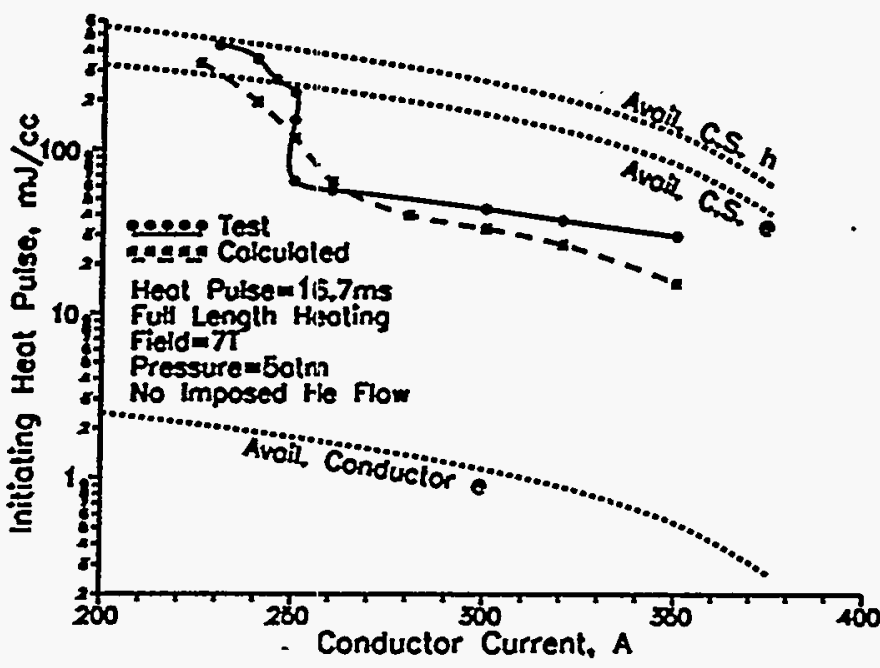

Fig. 2. ORNL NbTi triplex conductor stability, $3.1 \mathrm{~m}$ conductor length

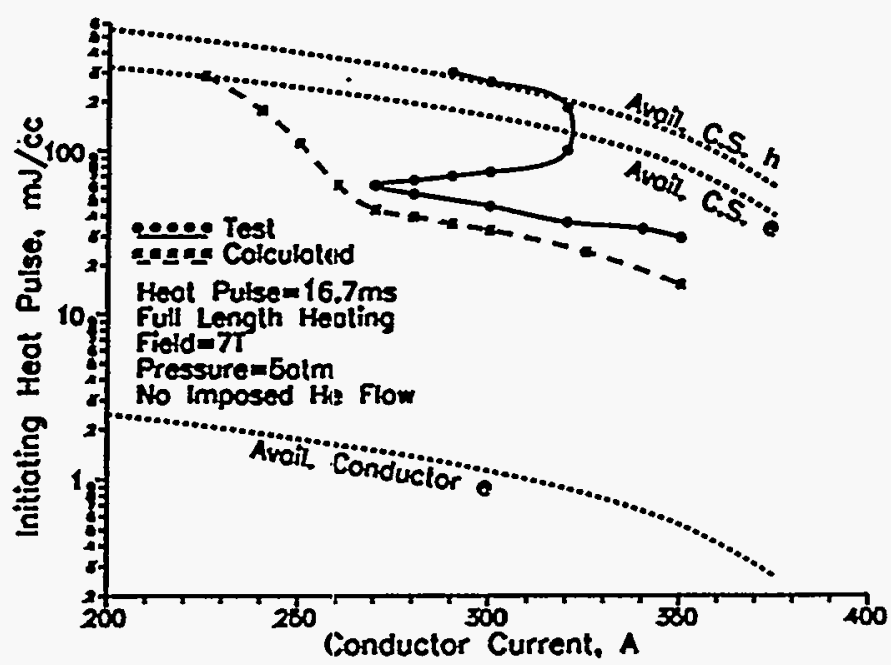

Fig. 3. ORNL NbTi triplex conductor stability, $3.8 \mathrm{~m}$ conductor length 


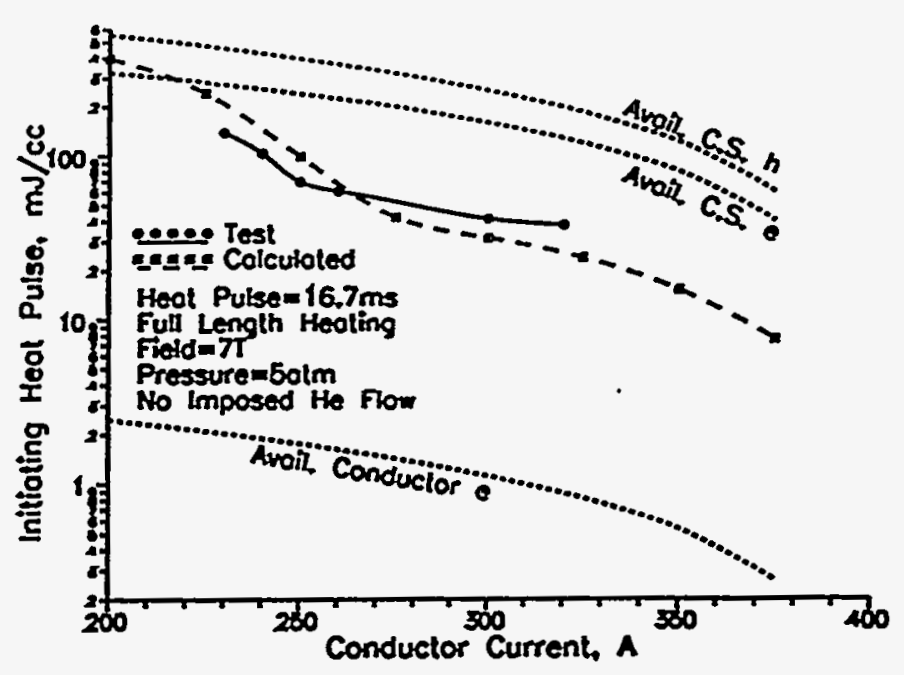

Fig. 4. ORNL NbTi triplex conductor stability, $4.8 \mathrm{~m}$ conductor length

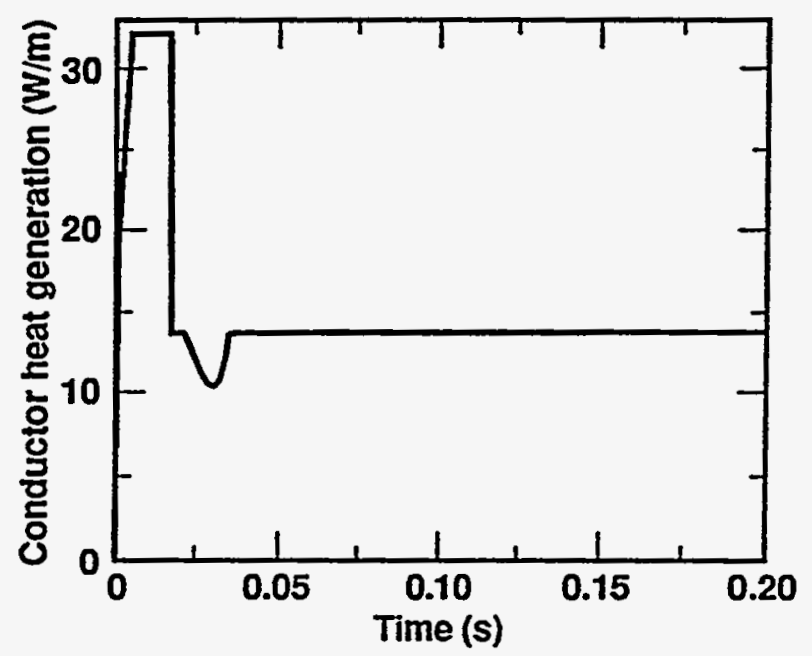

Fig. 6. ORNL NbTi triplex, heat generation at middle of conductor $250 \mathrm{~A} ; 1.8 \mathrm{~m}, 16.7 \mathrm{~ms}, 120 \mathrm{~mJ} / \mathrm{cc}$ heat pulse

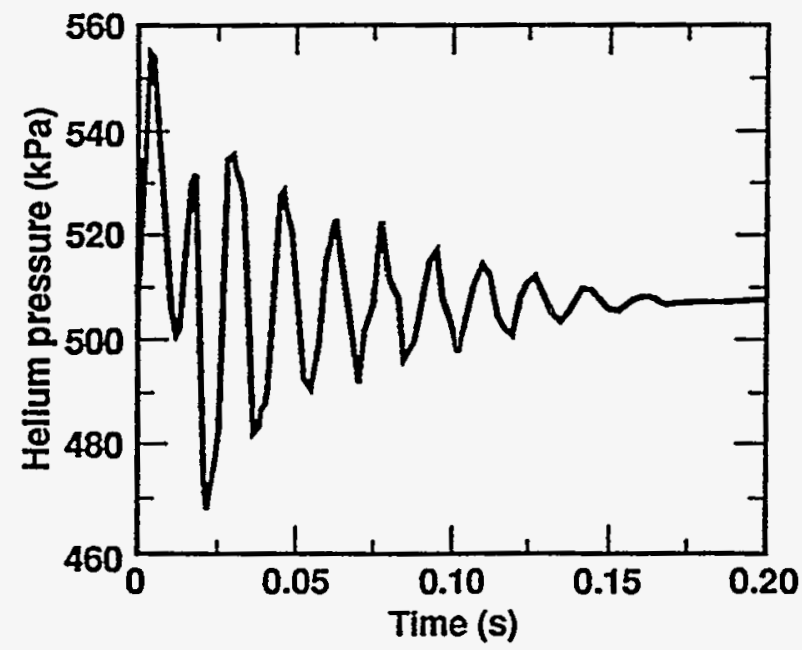

Fig. 8. ORNL NbTi triplex, pressure at middle of conductor $250 \mathrm{~A} ; 1.8 \mathrm{~m}, 16.7 \mathrm{~ms}, 120 \mathrm{~mJ} / \mathrm{cc}$ heat pulse

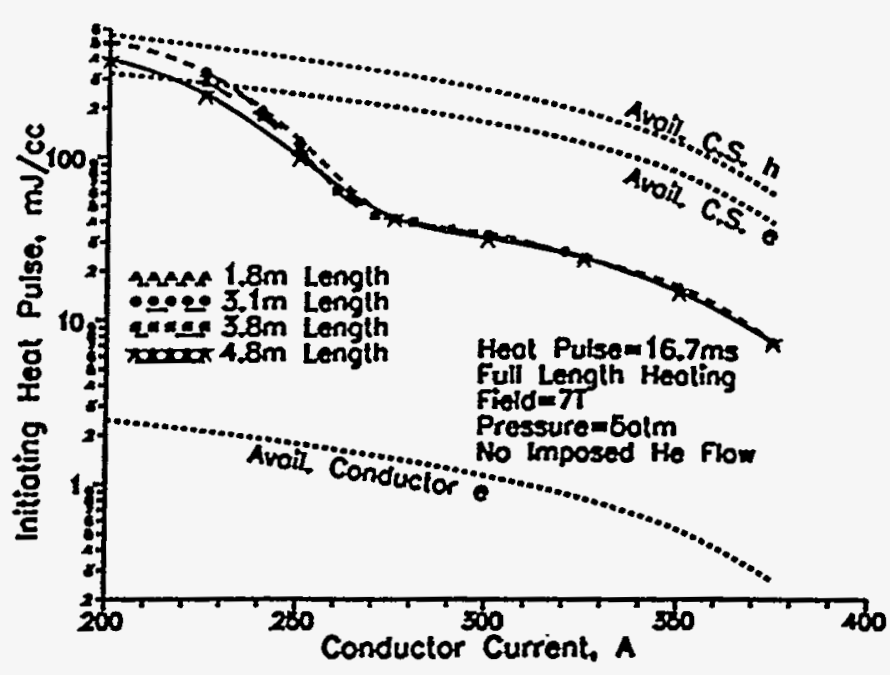

Fig.5. ORNLNbTi triplex conductor stability, calculated values

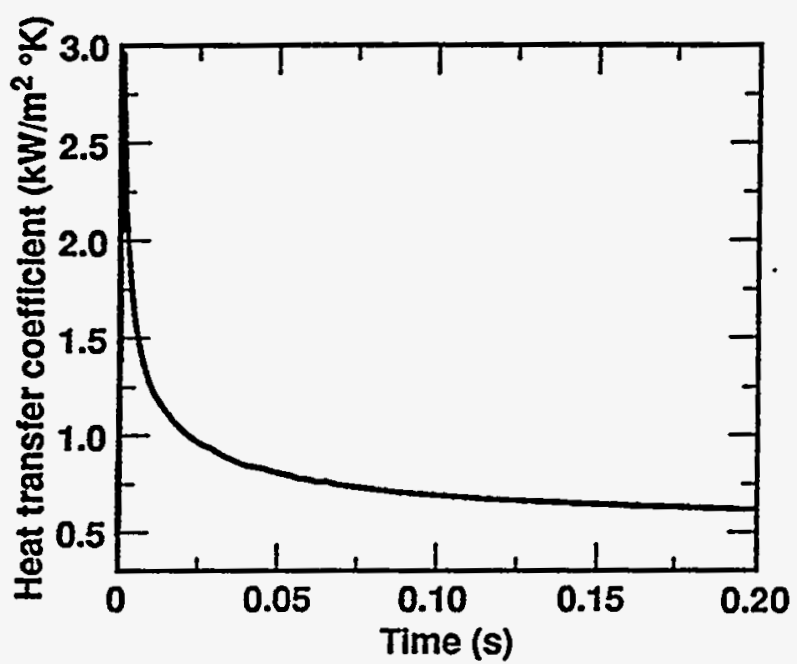

Fig. 7. ORNL NbTi triplex, heat transfer coefficient at middle of conductor $250 \mathrm{~A} ; 1.8 \mathrm{~m}, 16.7 \mathrm{~ms}, 120 \mathrm{~mJ} / \mathrm{cc}$ heat pulse

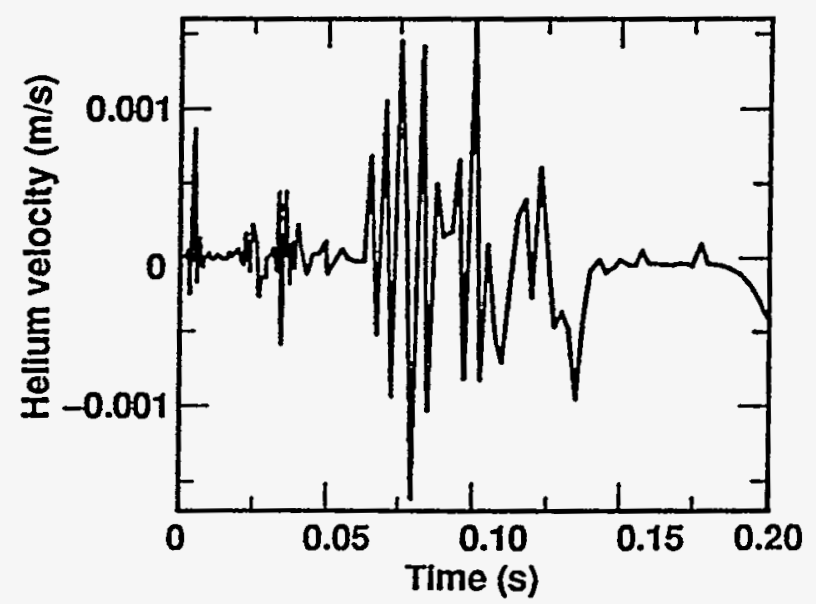

Fig. 9. ORNL NbTi triplex, velocity at middle of conductor $250 \mathrm{~A} ; 1.8 \mathrm{~m}, 16.7 \mathrm{~ms}, 120 \mathrm{~mJ} / \mathrm{cc}$ heat pulse 